Artículos Resultado de la Investigación

\title{
Observatorio de justicia regional. Justicia de género en Nariño. Año 2012
}

\section{Regional observatory of justice. Gender justice in Nariño 2012}

\section{Observatório regional de justiça. Justiça de género em Nariño 2012}

Isabel Goyes Moreno ${ }^{1}$ Sandra Montezuma Misnaza ${ }^{1}$

${ }^{1}$ Universidad de Nariño, Colombia

\begin{abstract}
Resumen
La presente investigación plantea un análisis sobre la justicia de género en Nariño, a partir del estudio de los fallos de las y los jueces penales del Distrito Judicial de Pasto en el año 2012. Entre sus resultados se advierte la persistencia de imaginarios patriarcales que limitan el reconocimiento de los derechos de las mujeres en igualdad; no obstante, es necesario mencionar que comienza a evidenciarse en algunos pronunciamientos judiciales un importante proceso de sensibilización de las y los operadores judiciales, situación que permite la exaltación de fallos ejemplarizantes, en la medida que han sido proferidos con perspectiva de género, los cuales deben divulgarse de manera amplia, para que se conviertan en antecedentes que iluminen la administración de justicia desde los derechos humanos de las mujeres hacia la búsqueda de la equidad e inclusión social.
\end{abstract}

Palabras clave: Nariño, justicia, estudios de género, observatorio, mujer

\begin{abstract}
Regional observatory of justice. Gender justice in Nariño 2012 are the persistence of patriarchal imaginary that limiting the recognition of equality women's rights however, however, it should be mentioned that begins to be evident, in some important judicial pronouncements, the sensitization process in judicial officials, which allowing the exaltation of exemplary failures, because they have been uttered with gender This pronouncement should be disclosed broadly, to become a history that illuminate the administration of justice from women's human rights throw the search of equity and social inclusion.
\end{abstract}

Key words: Nariño, justice, gender studies, observatory, woman

\section{Resumo}

Esta pesquisa apresenta uma análise sobre a Justiça de Género em Nariño, a partir do estudo das falhas dos juízes criminais e do distrito judicial de Pasto em 2012 Entre os resultados da persistência de patriarcal imaginário adverte que o limite reconhecimento dos direitos das mulheres em pé de igualdade, no entanto, deve ser mencionado que começa a ser evidente em alguns pronunciamentos judiciais de um processo importante e sensibilização dos funcionários judiciais, situação que permite a exaltação de decisões exemplares, na medida em que foram proferidas com uma perspectiva de gênero, que devem ser divulgados, para tornar-se uma história que iluminam a administração da justiça, dos direitos humanos das mulheres em direção à busca da equidade e inclusão social.

Palavras-chave: Nariño, justiça, estudos de gênero, observatório, mulher

Correspondencia: Isabel Goyes Moreno. Universidad de Nariño. revistalogos@policia.edu.co 


\section{Introducción}

La investigación del Observatorio de Justicia Regional, Administración de justicia de género en Nariño, se centra en los fallos proferidos por la justicia penal en la ciudad de Pasto, durante el año 2012. Por esta razón, es la violencia contra la mujer en diversas y aberrantes expresiones, así como la evaluación subjetiva de los operadores jurídicos a la luz del ordenamiento jurídico colombiano, el objeto que concentra la indagación y reflexión de este estudio.

En esa perspectiva se hace necesario precisar que la violencia de pareja como problema social se encuentra en proceso de construcción, que su teorización es reciente, pues data de los años sesenta del siglo $X X$ y en el camino de su identificación ha encontrado diversos obstáculos, desde los culturales patriarcales de la ciudadanía, los agresores y las víctimas, hasta los hermenéuticos e ideológicos de los administradores de justicia.

Conviene recordar al respecto, que gracias a la gestión de los movimientos feministas fue posible abrir las puertas de los hogares y permitir que la vida doméstica fuese sometida al escrutinio de la ciudadanía, lo que permitió observar que el ejercicio de la indiscutible autoridad paterna encerraba conductas reprochables, sancionadas finalmente como delictivas. Denominaciones como violencia doméstica, violencia conyugal, violencia familiar, violencia en las relaciones de pareja, violencia basada en género, femenicidio, se constituyen en evidencias de las transformaciones culturales y normativas, las que pasaron, al decir de Ariza Sosa (2012) de "inapelables a intolerables", esto es, aquellas violencias que se entendieron como consustanciales a instituciones como la familia y el matrimonio, se han transformando, gracias al reconocimiento y consagración de los derechos de las mujeres, en conductas delictivas que deben ser prevenidas, reparadas y sancionadas.

La administración de justicia se convierte de este modo,

"en una herramienta fundamental con la que hoy en día cuentan las mujeres para materializar la protección de sus derechos, exige la aplicación de un verdadero enfoque de género. Sin embargo, la realidad refleja innumerables casos, principalmente de violencia intrafamiliar y sexual que no son judicializados (...)". (Goyes, Montezuma, 2012, p.17)
La justicia colombiana, de conformidad con el mandato del Estado Social de Derecho, está comprometida con la igualdad de todas y todos sus integrantes (Artículo 13) y de manera especial, con la igualdad de oportunidad entre hombres y mujeres (Artículo 43). Este principio constitucional guarda coherencia con las convenciones internacionales, tales como la CEDAW (ratificada por ley 51 de 1981) o la de Belén Do Pará (ratificada por ley 248 de 1995). En la primera, de manera expresa se reconoce la discriminación, prohibiendo tanto los actos intencionales o indirectos de discriminación y en la segunda se consignan mecanismos para prevenir, sancionar y erradicar la violencia basada en género.

A pesar de disponer de una marco jurídico favorable a la equidad de género, las mujeres, por su vulnerabilidad social derivada de la histórica discriminación, enfrentan dificultades reales para acceder a la administración de justicia y cuando, superando múltiples obstáculos, lo logran, se encuentran con operadores jurídicos de mentalidad patriarcal que desconocen sus derechos y que se mantienen atados a viejos esquemas.

Por esa razón, en el documento "El progreso de las mujeres en el mundo, en busca de justicia 2011-2012", se leen afirmaciones tan contundentes como la siguiente:

"La implementación eficaz de las leyes y garantías constitucionales es un desafío para el Estado social de derecho. Con frecuencia los procedimientos que las mujeres siguen para acceder al sistema judicial formal o para reivindicar sus derechos, se interrumpe debido a la falta de capacidad del sistema y a las actitudes discriminatorias de quienes proporcionan los servicios, como la policía y los empleados y funcionarios de la rama judicial".

Las Altas Cortes en Colombia han asumido el liderazgo, el proceso de capacitación y las formulaciones públicas que evidencian un serio compromiso para otorgar a la administración de justicia la perspectiva de género.

"Un derecho moderno, nuevo y acorde al respeto por los derechos fundamentales que trae la Constitución Política (...) debe incluir una perspectiva de género, que tome en cuenta la desigualdad que existe entre hombres y mujeres en el contexto social". (Díaz, 2011, p. 1) 
Registrar, evaluar y divulgar los avances y/o retrocesos en la defensa y reconocimiento de los derechos de las mujeres, es una labor investigativa que les corresponde a la academia, con la finalidad de contribuir a visibilizar tanto las sentencias regresivas, como aquellos fallos ejemplarizantes, que se convierten en los nuevos paradigmas del derecho judicial. La justicia puede mantener y reproducir las desigualdades sociales, pero también puede ser un medio eficaz para el reconocimiento de derecho y la transformación pacífica de una realidad.

\section{Objetivos}

Identificar las principales tendencias en los fallos proferidos por las y los jueces penales municipales, de Circuito y la Sala Penal del Tribunal Superior del Distrito Judicial de Pasto, en el año 2012 en casos de violencia contra mujeres.

Destacar aquellos pronunciamientos donde la argumentación se fundamenta en el reconocimiento de los derechos humanos de las mujeres y en la valoración de la situación concreta de vulneración a que se encuentran sometidas.

\section{Metodología}

Esta iniciativa se desarrolla en el marco del Observatorio de Justicia Regional de Nariño, proyecto "Informe Regional: Derechos Humanos de las Mujeres y Justicia de Género en Nariño" del grupo de investigación Derecho, Justicia y Región - Dejure. Universidad de Nariño.
La investigación contó con una etapa inicial orientada a la identificación de los asuntos que referían hechos de violencia contra mujeres; para ello se revisó la totalidad de las sentencias proferidas por los despachos judiciales objeto de análisis en el periodo 2012. Los fallos que cumplían con estas características, fueron diligenciados en la ficha técnica que constituye un software especializado, propiedad del Observatorio, con el propósito de medir, estandarizar y cuantificar las características particulares de los asuntos, tales como: tipo de delito, categoría del victimario, parentesco con la víctima, sanción impuesta, tipo de condena, entre otros.

Las sentencias identificadas fueron analizadas en su totalidad, con el propósito de estudiar las principales tendencias de las y los jueces en sus fallos, la remisión a fuentes normativas, jurisprudenciales y doctrinarias y la perspectiva de género inmersa en sus decisiones. Finalmente la investigación resalta los fallos ejemplarizantes identificados y analizados en el marco del presente estudio.

\section{Resultados}

Fueron identificadas 57 sentencias que referían casos de violencia contra mujeres, con las siguientes características:

\section{Juzgados Penales Municipales}

Los Juzgados Penales Municipales, para el año 2012, fallaron 15 casos relacionados, así:

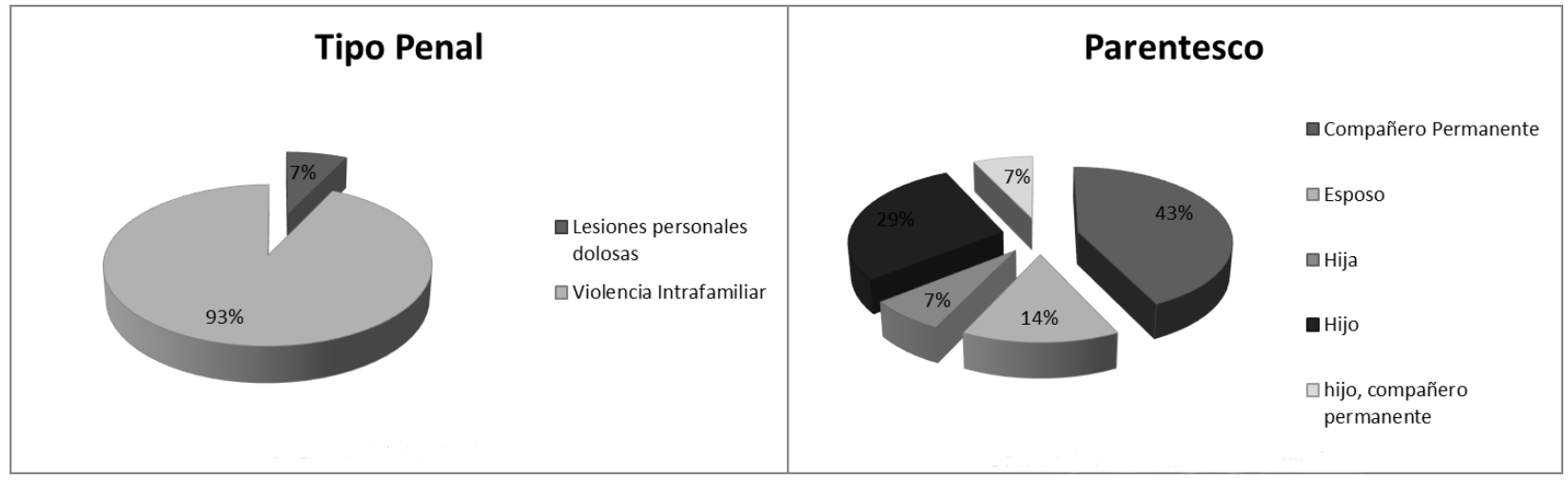


En el año 2012, el $93 \%$ de los delitos cometidos contra mujeres corresponde a episodios de violencia intrafamiliar, mientras los ilícitos judicializados por lesiones personales se reducen a un $7 \%$. La agredida en todos los casos es la compañera, esposa o madre y los agresores son hombres a quienes la unen vínculos de parentesco por afinidad, consanguinidad y en todos los casos de afecto y convivencia, circunstancia que incrementa la violencia, por cuanto no solo se trata del daño físico, sino de las secuelas sicológicas, morales y espirituales que afectan a la víctima de manera permanente. La violencia familiar refirió episodios repetitivos y frecuentes. Existen, en este sentido, imaginarios culturales según los cuales la violencia es parte connatural de las relaciones de pareja, de los vínculos del afecto, que justifican aquellas afirmaciones populares, según las cuales, "si estoy feliz, es porque algo malo va a ocurrir". Frases como estas, repetidas e interiorizadas, justifican las violencias que se generen al interior de las familias.

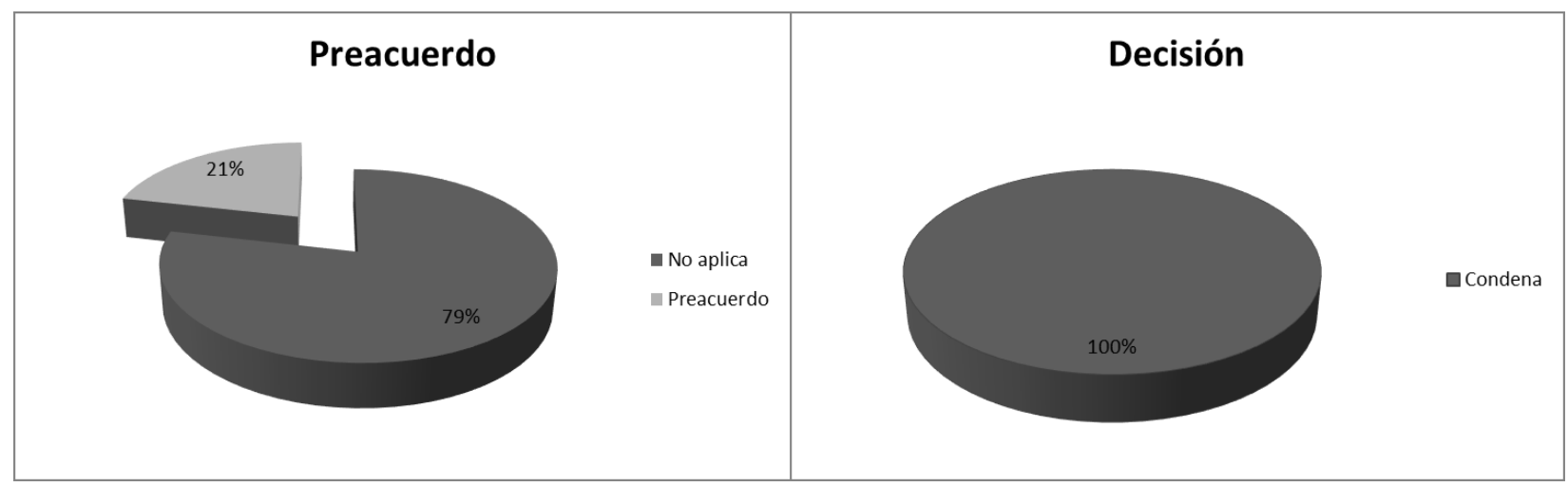

El $100 \%$ de las sentencias emitieron decisión de condena, dentro de ellas, el 79 \% obedeció a un proceso de preacuerdo suscrito por la Fiscalía con el indiciado, mientras el 21 \% terminaron en instancia de juicio. Como se puede deducir fácilmente, la posibilidad legal de agilizar la justicia mediante esta figura, puede entenderse como una conquista social con miras a reducir la impunidad y la morosidad, pero cuando se trata de asuntos de violencia basada en género, existe el peligro de que en aras de una culminación ágil, se sacrifiquen derechos o se oculten realidades de subordinación y sometimiento inaceptables.

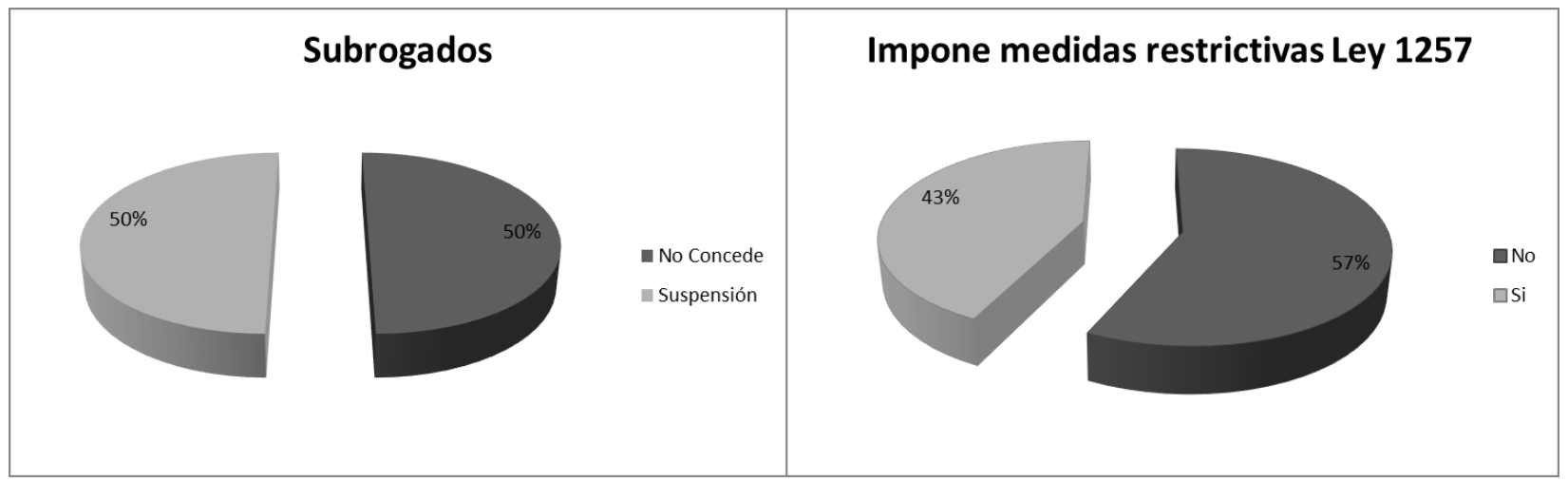


En el $50 \%$ de los asuntos se concedió la figura de los subrogados penales, esto es la suspensión condicional de la pena y la prisión domiciliaria, mientras el 50 \% restante ordenó la ejecución total de la pena.

Se trata de un altísimo porcentaje en el que el subrogado de la prisión domiciliaria puede acarrear la revictimización, puesto que obligar a compartir la vivienda con el agresor de una manera más intensa por la imposibilidad del agresor de abandonar la casa, puede intensificar la violencia intrafamiliar que se pretende combatir y sancionar.

Dentro de los hallazgos importantes de la presente investigación se destacan la imposición de medidas restrictivas ordenadas por la Ley 1257 de 2008, especialmente las consagradas en los artículos 17 y 24, las que fueron aplicadas en el $43 \%$ de los casos.

Las condenas impuestas se clasificaron teniendo en cuenta en tiempo de condena, en los siguientes rangos:

\section{Tiempo de condena}

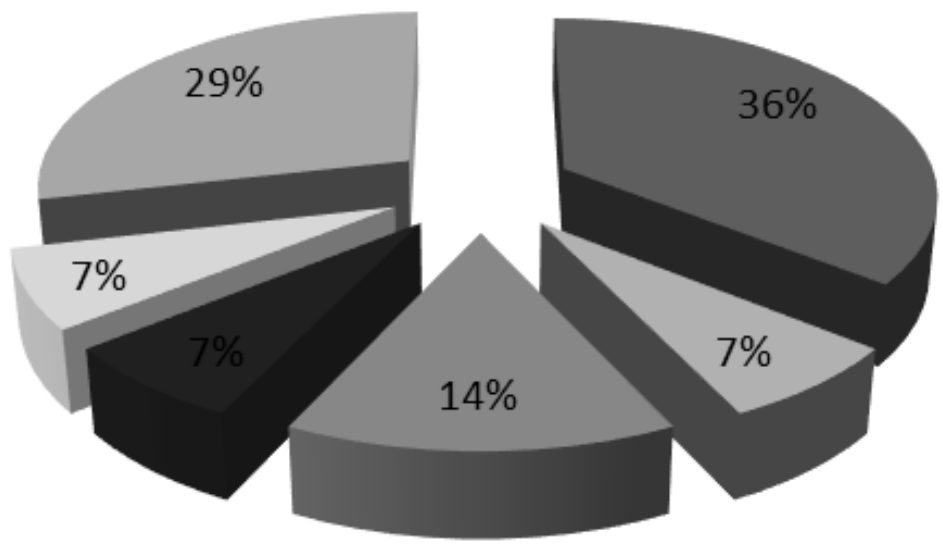

De 1 a 2 años

De 2 a 3 años

De 3 a 4 años

De 5 a 6 años

Inimputable

Menos de 1 año

En el $36 \%$ de los casos, la condena oscila entre 1 y 2 años, mientras el $29 \%$ de las condenas se reducen a un periodo inferior a un año. En el 14 $\%$ de los asuntos, la pena se ubica entre los 3 y los 4 años. Las condenas entre 2 a 3 años y 5 a 6 años, representan un $7 \%$ cada uno. Los anteriores datos demuestran que existe ya una conciencia acerca de la violencia intrafamiliar como delito que merece ser castigado y que los agresores, lejos de ejercer autoridad, violentan los derechos humanos de las mujeres. Estas estadísticas también reflejan el incremento de las denuncias de esta clase de delitos, que con anterioridad no se llevaban a los estrados judiciales, bajo el criterio de que los asuntos domésticos les corresponden exclusivamente a los integrantes del grupo familiar y que es allí donde deben encontrarse las mejores soluciones. Aún hoy persiste ese imaginario y son muchos los casos que no llegan a los entes judiciales o de defensa de los derechos humanos. 


\section{Tiempo transcurrido desde los hechos hasta la decisión}
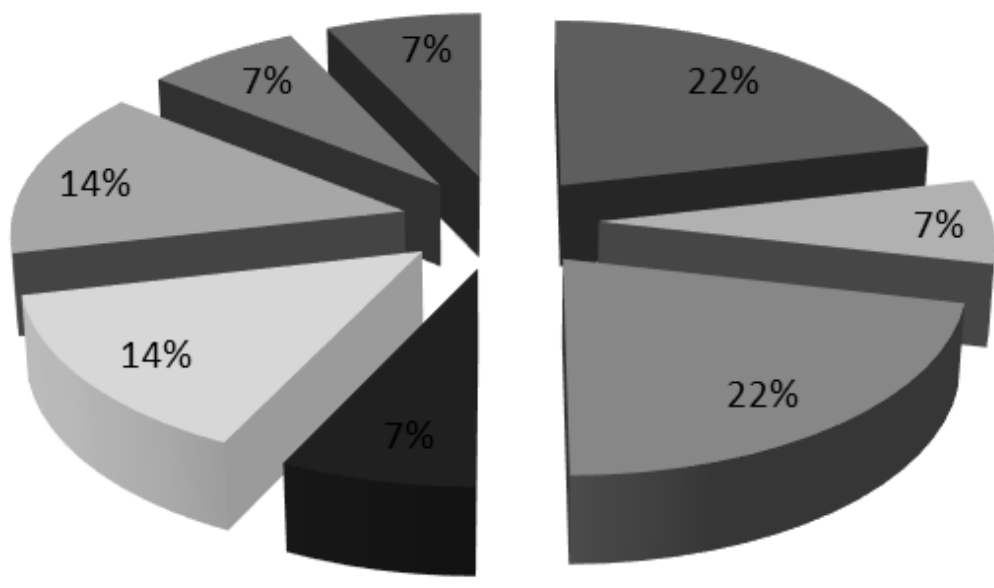

De 1 a 2 meses

De 2 a 3 meses

De 3 a 4 meses

De 4 a 5 meses

De 5 a 6 años

De 5 a 6 meses

De 7 a 8 meses

De 9 a 10 meses

Uno de los problemas más sensibles para quienes acuden a la administración de justicia, es la aspiración de que esta actúe de manera pronta. Al analizar el periodo de tiempo transcurrido desde los hechos hasta la decisión, los resultados dan cuenta de un porcentaje significativo de asuntos fallados en un periodo inferior a seis meses, situación que obedece a la terminación anticipada del proceso en virtud de la figura del preacuerdo, no obstante, se observa con preocupación que el $14 \%$ de los asuntos analizados tardaron entre cinco y seis años en obtener sentencia. De tal forma que, si se resalta la validez de los preacuerdos como una estrategia de eficiencia judicial, no queda sino advertir que dichas medidas deben ir respaldadas por el respeto al derecho de las víctimas. 


\section{Funcionario/a Judicial}

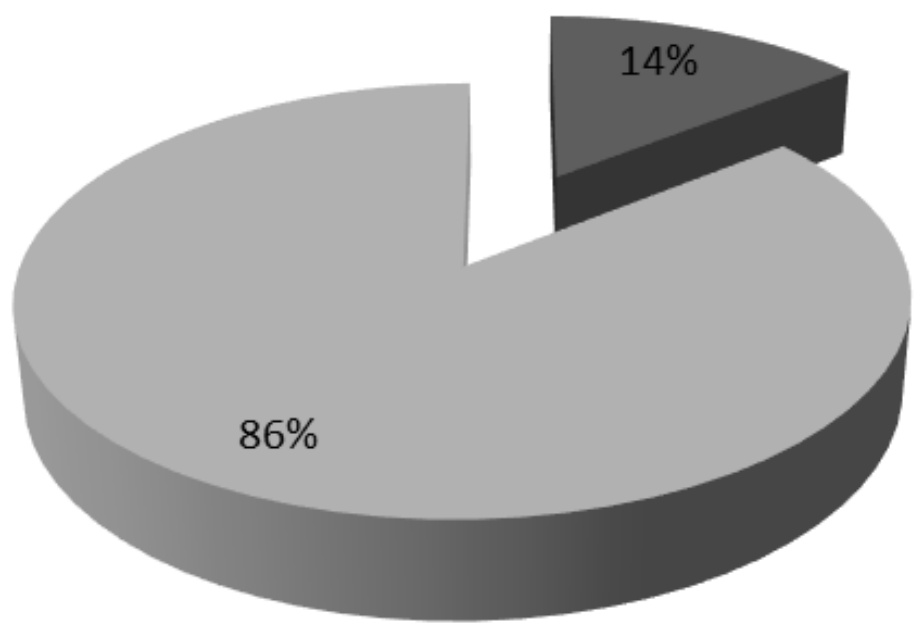

Juez

Jueza

Una circunstancia casual e interesante, es que en la ciudad de Pasto, en esta clase de proceso, las víctimas al igual que quienes administraron justicia fueron mujeres. En efecto, en el $100 \%$ de los asuntos, la víctima fue una mujer mayor de edad. Por su parte, en el $86 \%$ de los casos de violencia tramitados ante los Juzgados Municipales de Pasto, el fallo fue emitido por una mujer, en su calidad de jueza, situación esta que podría llevar a presumir que existe un mayor compromiso y comprensión con la situación de vulnerabilidad y sometimiento que experimentan las mujeres. Los expedientes demuestran que esto no es así, que el conocimiento y empoderamiento sobre los derechos de la mujer no son innatos, que en muchos casos predominan los aprendizajes patriarcales, los cuales se practican de manera inconsciente y con independencia del sexo.

\section{Juzgados Penales del Circuito}

De igual manera, en los 35 casos ventilados ante los Juzgados Penales del Circuito durante el año 2012, la víctima fue una mujer y los delitos que se perpetraron en su contra se clasifican así: 


\section{Tipo Penal}

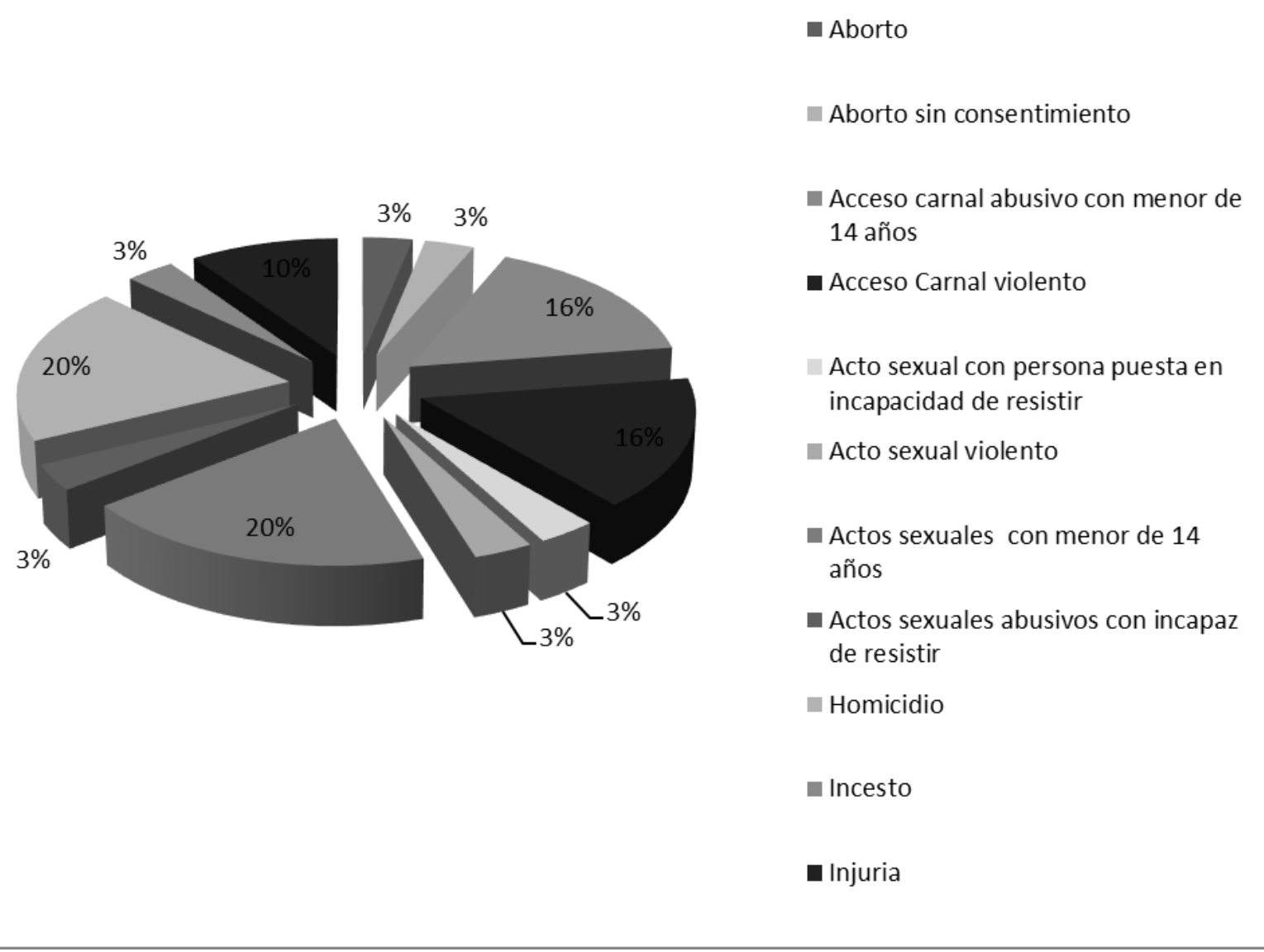

Se observa con preocupación que el $20 \%$ de los asuntos analizados en estos despachos corresponden a homicidios, hallazgo que se equipara con el delito de actos sexuales con menor de 14 años, representado por idéntico porcentaje (20\%), seguido del ilícito de acceso carnal violento que representó un $16 \%$, igual que el acceso carnal abusivo con menor de 14 años; continuaron con menor porcientos el acto sexual con persona puesta en incapacidad de resistir, acto sexual violento y actos sexuales abusivos con incapacidad de resistir e incesto, todos con un $3 \%$ en cada caso.

Sobresale dentro de estos resultados, los procesos judicializados por el delito de injuria que representan el $10 \%$, conductas que obedecen principalmente a incidentes entre parejas y exparejas, por aborto y por aborto sin consentimiento, todos con un $3 \%$. 


\section{Edad de la víctima}

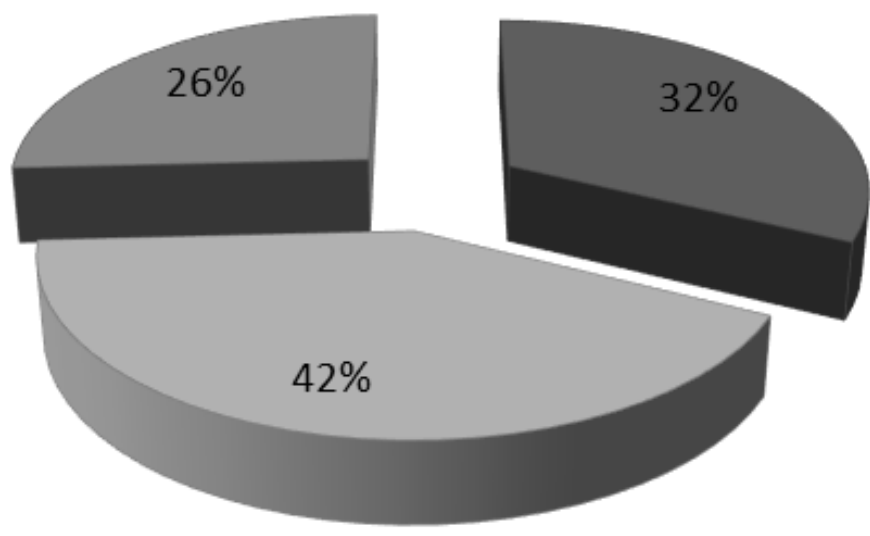

Mayor de edad

Menor de 14 años

Menor de 18 años

Infortunadamente y como consecuencia del anterior hallazgo, en el $42 \%$ de los casos, la víctima fue una niña menor de 14 años, seguidas del $26 \%$ de episodios en que las víctimas fueron menores de 18.

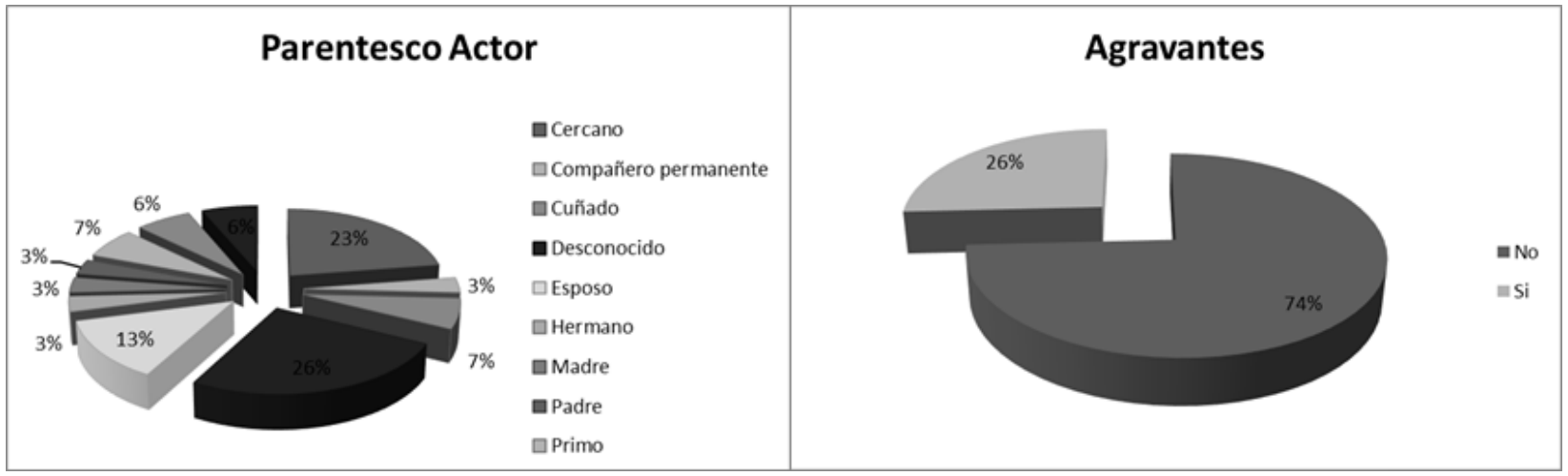

Los tipos penales antes referidos fueron cometidos en un $26 \%$ por hombres desconocidos, en un $23 \%$ por cercanos a la víctima, en un $13 \%$ por el esposo, en un $7 \%$ por el cuñado, en un 7 $\%$ por el primo, en un $6 \%$ por el profesor y en un $3 \%$ por el padre, el hermano y el compañero permanente, en cada evento, situación que no se compadece con el reducido $26 \%$ de casos en los cuales la conducta se agravó en razón del vínculo de la víctima con el victimario, condición que obliga la activación de alertas, a la hora de aplicar el juicio de tipicidad para sancionar esta 
clase de conductas.

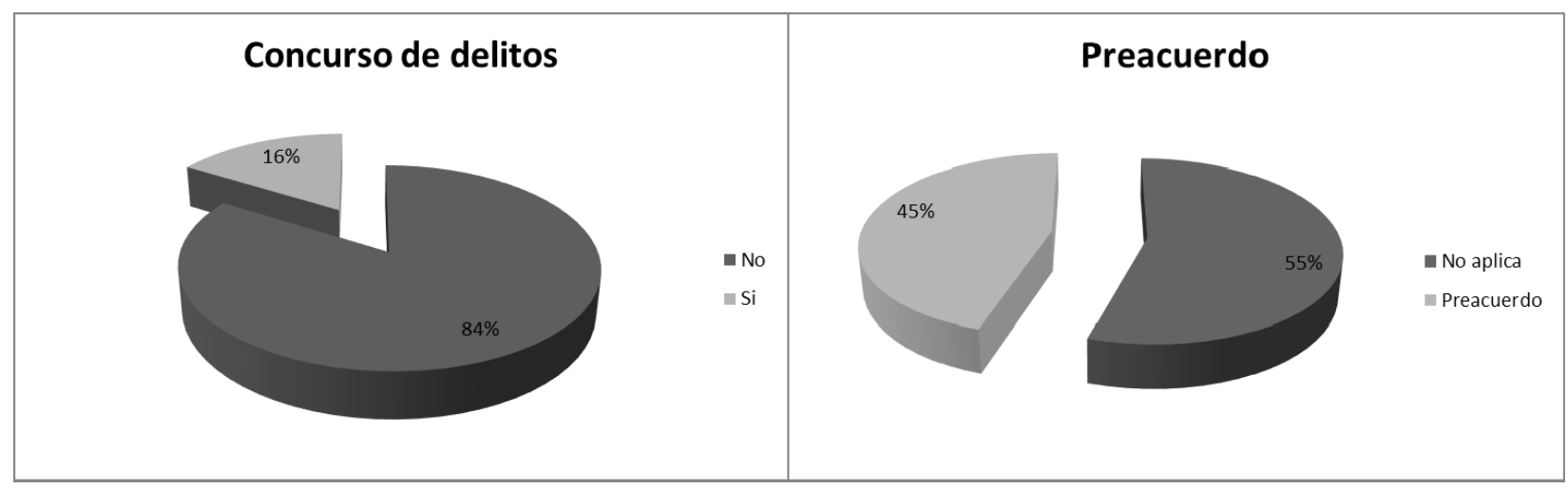

En el $16 \%$ de los casos, la investigación resalta la presencia de varios tipos penales, principalmente orientados a sancionar el concurso homogéneo sucesivo, de manera particular en conductas de agresiones sexuales, mientras en el 84 \% de los asuntos, la acusación se reduce a una sola conducta.

El $45 \%$ de los asuntos terminan anticipadamente con la figura del preacuerdo, situación que modifica radicalmente la proporcionalidad entre la gravedad de la conducta en el inicio del proceso y las características de la sanción que manifiesta el fallo, condición que obliga el estudio acerca de la utilización que el ente acusador está haciendo de esta herramienta frente a este tipo de delitos.

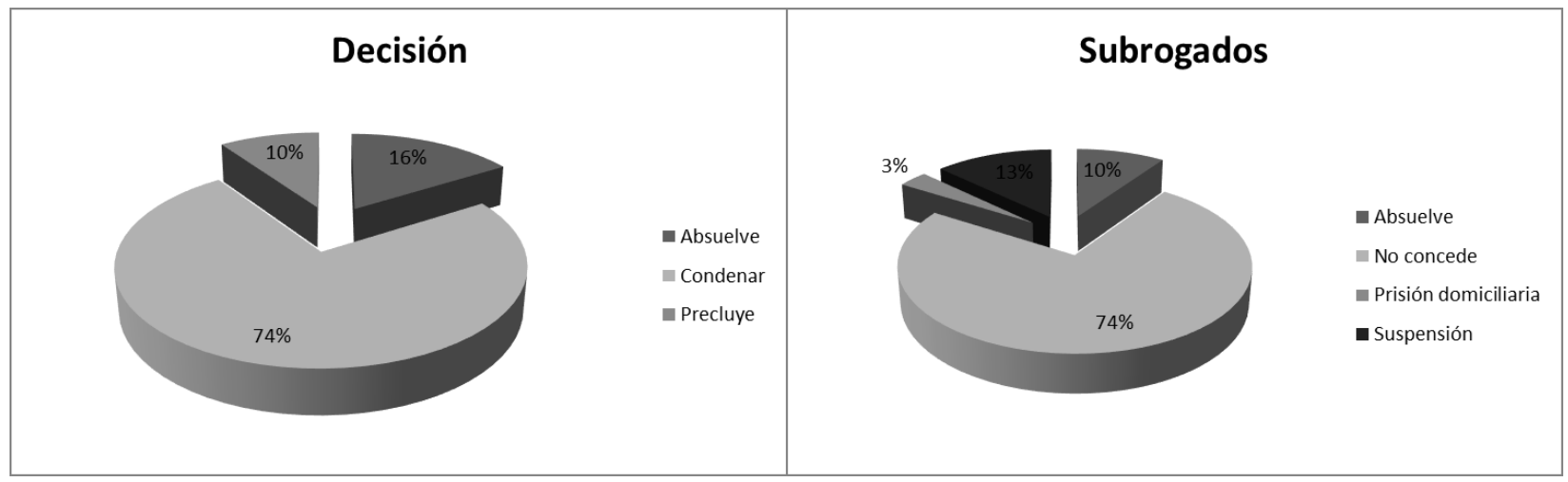

En el $74 \%$ de los casos, la decisión fue de condena y dentro de esta, el $26 \%$ concedió subrogados penales; $3 \%$ con prisión domiciliaria y el $13 \%$ restante, mediante la suspensión provisional de la pena en establecimiento carcelario. 


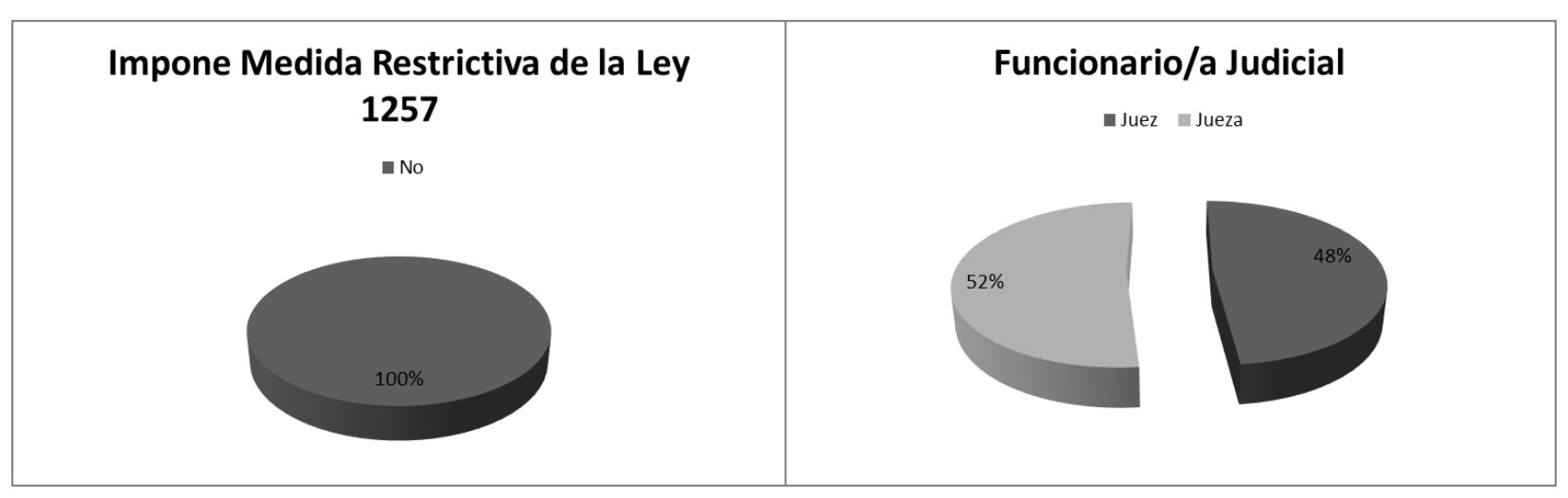

En ninguno de los asuntos analizados en los Despachos Judiciales del Circuito de Pasto se impusieron medidas restrictivas de las que ordena la Ley 1257 de 2008, aspecto que llama la atención y que debe ser analizado con cuidado por los administradores de justicia.

En el año 2012, el $52 \%$ de los despachos judiciales se encontraban a cargo de una jueza. Nuevamente aquí aparece la situación

\section{Tribunal Superior del Distrito Judicial de Pasto - Sala Penal.}

En segunda instancia, este Despacho decidió 7 casos relacionados, así:
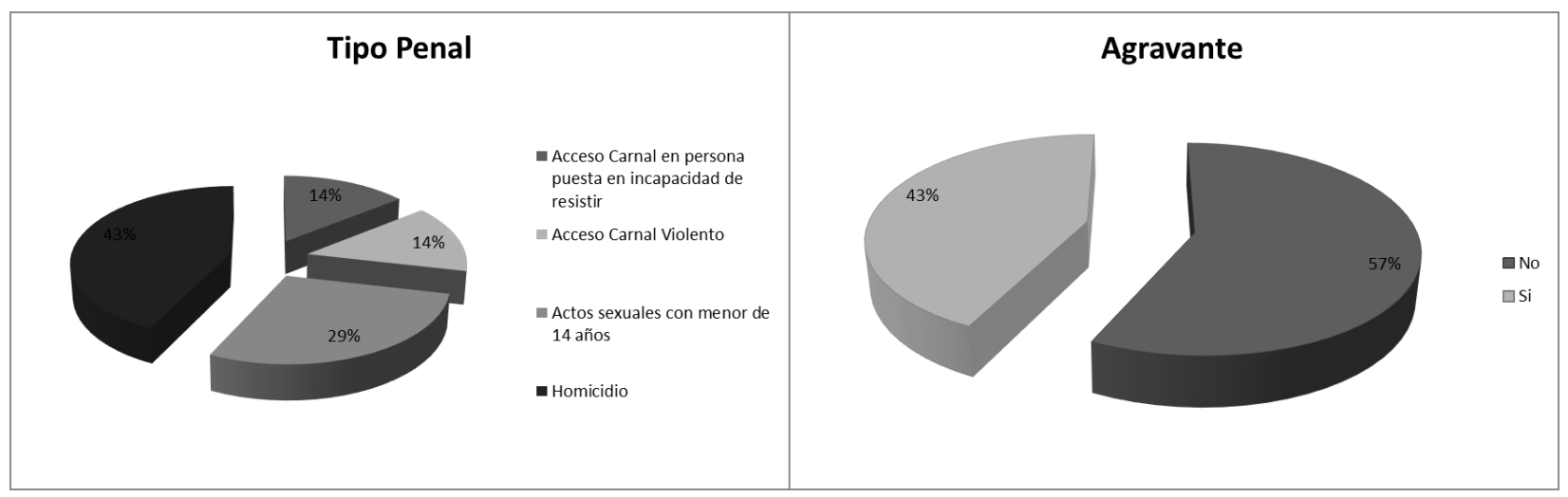

El $43 \%$ de las conductas delictivas falladas en sede del Tribunal obedecen a homicidios, el $29 \%$ se juzgaron por actos sexuales con menor de catorce años, el $14 \%$ por acto sexual violento y el $14 \%$ por acceso carnal en persona puesta en incapacidad de resistir, no se conoció de asuntos fallados en segunda instancia por los punibles de lesiones personales o violencia intrafamiliar. En el $43 \%$ de los casos, la pena contempló la aplicación de agravantes. 


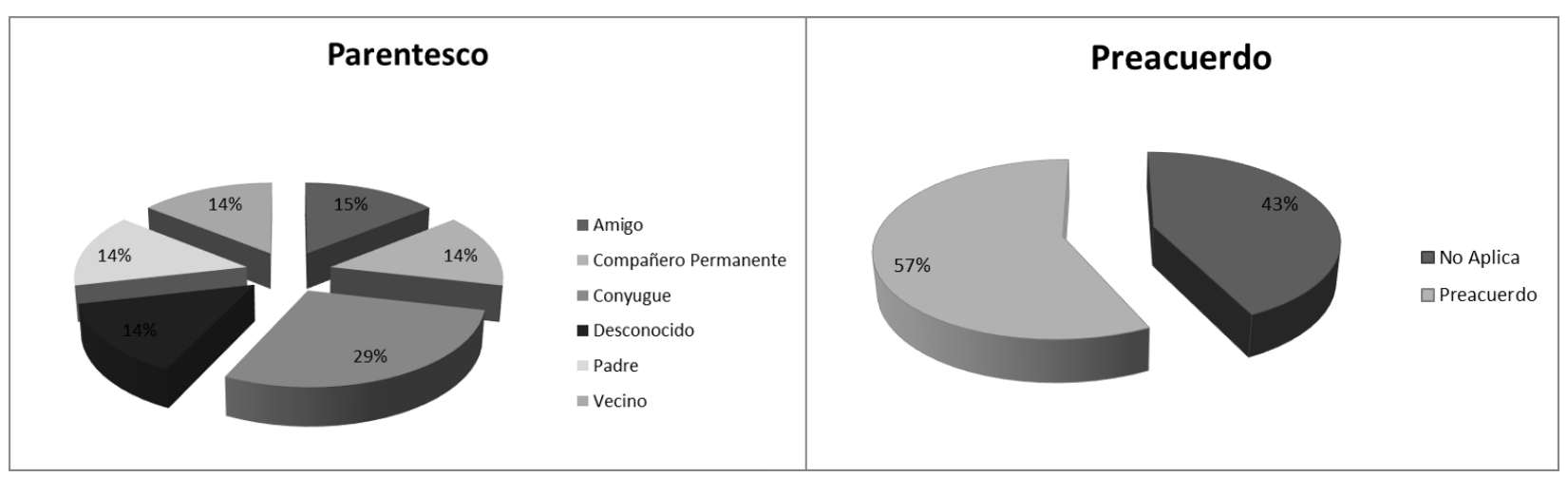

Dentro de la población analizada, en el $29 \%$ de los casos el agresor era el cónyuge de la víctima, el $14 \%$ su compañero permanente, el $15 \%$ fue un amigo, mientras el padre, el vecino y un desconocido representan el $42 \%$ restante, sumando $14 \%$ cada uno.

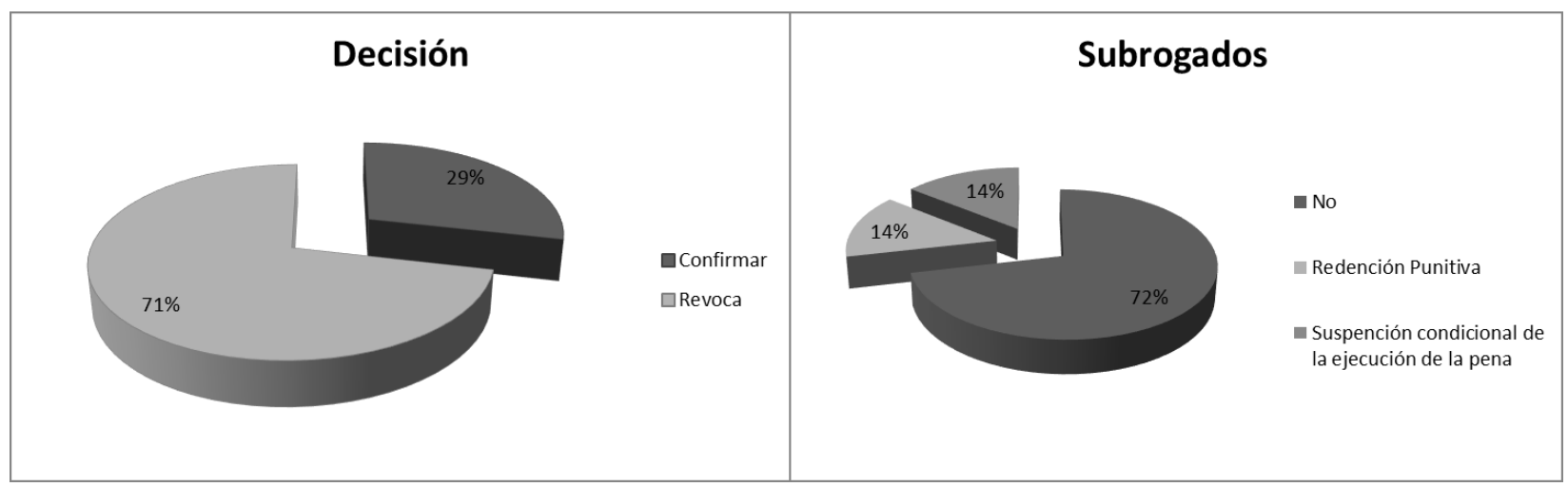

Tan solo el $29 \%$ de los casos fallados en segunda instancia por el Tribunal Superior confirmaron la decisión, mientras el 71 \% sancionó de manera diferente la conducta sometida a su conocimiento. Por su parte, en el
$28 \%$ de los fallos se aplicó el beneficio de los subrogados penales, $14 \%$ de ellos con redención punitiva y el $14 \%$ restante a través de suspensión condicional de la ejecución de la pena. 


\section{Tiempo transcurrido desde los hechos hasta la decisión}

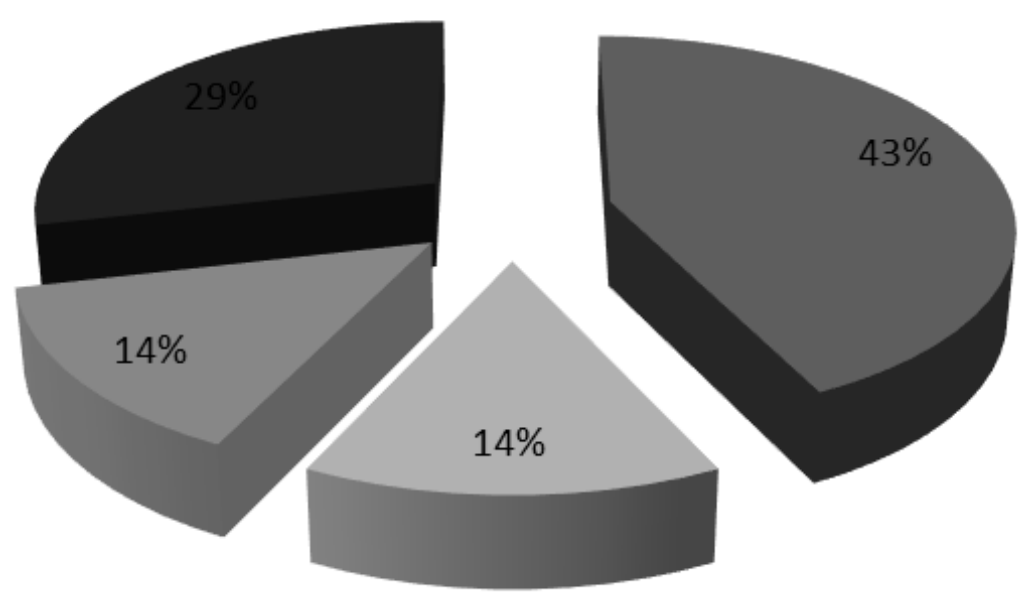

- De 1 a 2 años

De 4 a 5 años

De 5 a 6 años

- No hay datos

La pena que sancionó los delitos fallados ante este Estrado se clasifica así: entre 15 y 16 años, el $29 \%$; entre 17 y 18 años, el $15 \%$; entre 9 y 10 años, el $14 \%$; entre 5 y 6 años, el $14 \%$ y entre 2 y 3 años, $14 \%$ igualmente. 


\section{Funcionario/a Judicial}

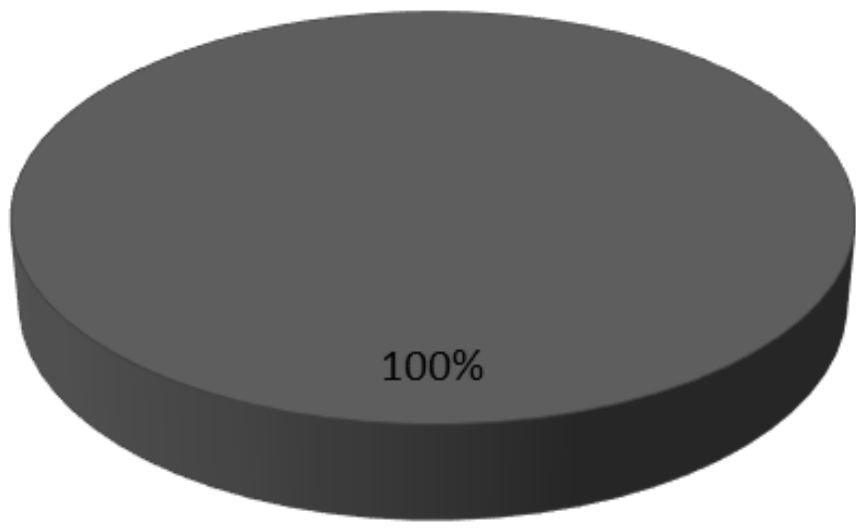

Magistrado

El $100 \%$ de este cuerpo colegiado estuvo integrado por magistrados.

\section{De las tendencias de las y los jueces al fallar.}

Del análisis cualitativo de los fallos que se han relacionado, es posible identificar algunas tendencias ideológicas, culturales y jurídicas, que se presentan a continuación:

Aún persisten imaginarios patriarcales en las y los jueces del Distrito Judicial de Pasto que se reflejan en los fallos analizados, sus efectos principalmente se evidencian en la tendencia al valorar pruebas determinantes en el proceso, la inobservancia de agravantes y la consecuente aplicación de subrogados penales que promueven graves procesos de revictimización.

Dentro de este contexto, han ocupado especial atención varios argumentos impulsados desde la defensa, la fiscalía y el Juzgado, a la hora de lograr la imputación del delito, argumentos que ratifican formas de discriminación contra las mujeres, que condicionaron el propósito de igualdad que debe permear la administración de justicia, dentro de los cuales se destacan:
"Los elementos de prueba recopilados demuestran que el sentenciado es responsable de la muerte violenta de Sandra, en hecho ocurrido el día 25 de diciembre de 2006, falleciendo por shock hipovolémico, producido por múltiples heridas de arma corto punzante, punible cometido en circunstancias de ira provocada por el rechazo sexual y la agresión física que la ofendida le ocasionó a Heiman, comportamiento que esta Judicatura considera grave e injustificado, pues no puede perderse de vistas que fue la occisa quien provocó al sentenciado, para luego negarse a acceder a sus pretensiones sexuales porque no tenía dinero para pagarle".

“(... )en consecuencia en este caso particular dadas las modalidades de la conducta punible, perpetrada por el sentenciado en estado de ira, provocado por la propia víctima y a pesar de la gravedad que reviste la vulneración del principal bien jurídico del ser humano: la vida, estimamos que es factible disminuir la mitad de la pena, que en este caso serían 13 meses quedando una pena definitiva de 13 meses y 1 día de prisión". (Juzgado Penal del Circuito, 2007)

“(...)así las cosas, si bien el hecho atribuido al procesado es de una gravedad suma, pues 
constituyó un atentado contra el más elemental de los derechos, deparando la temprana desaparición de una persona con una prolongada expectativa de vida, lo cierto es que las pruebas aportadas al plenario indican que el motivo determinante del hecho lo constituyo el desamor que (...) le deparó a su victimario; es decir, que los motivos fueron de carácter pasional, donde no se avizora la preparación ponderada del hecho, sino por el contrario, la comisión intempestiva a impulsiva del mismo, propio de este tipo de injustos donde la pasión desborda los frenos inhibitorios de la persona y la lleva a perpetrar hechos que bajo otras circunstancias jamás estaría en posibilidades de cometerlos. Por ello, dadas las circunstancias anotadas precedentemente, esta judicatura estima que al procesado ha de imponérsele la pena mínima contemplada para este injusto, es decir, ciento cincuenta y seis (156) meses de prisión." ( Juzgado Penal del Circuito de Pasto, 2009)

"Y aunque podría pensarse que la rápida salida del lugar del hoy sentenciado, es un indicio de su responsabilidad en el punible que se le endilga y su intención de evadir la justicia, como acertadamente lo señala la defensa, atendiendo las reglas de la experiencia y la sana critica, no es menos cierto que la reacción desmesurada de MONICA llevó al señor Cruz a salirse de sus casillas y a querer alejarse de ella, y si de querer perpetrar desde el principio un injusto como el que se le formula, bajo el entendido de que la denunciante se encontraba en estado de inconsciencia o incapacidad de resistir, el procesado se hubiera evitado pagar el valor de habitación del motel, donde perfectamente podían identificarlo, y hubiera conducido a la víctima a un paraje solitario y sin testigos, en el que libremente podría haber abusado de ella, abandonándola después". (Juzgado Penal del Circuito de Pasto, 2011)

Haciendo justicia a la realidad de los expedientes analizados, es necesario también destacar lo que se ha denominado fallos ejemplarizantes, los que se presentan y analizan a continuación.

\section{Fallos ejemplarizantes}

A pesar del panorama antes descrito, para el año 2012, se percibe la aplicación de un importante proceso evolutivo de reconocimiento hacia los derechos de las mujeres; la vigencia de los derechos fundamentales fuertemente permeados por estándares internacionales, es cada vez más evidente, mientras la materialización del concepto de equidad se traduce en la protección de sus derechos y el reconocimiento de su condición de seres humanos, con idénticas garantías y deberes en los ámbitos públicos y privados.

La referencia a la Ley 1257 de 2008, a la normatividad relacionada y al bloque de constitucionalidad es cada vez más recurrente, la fuerza del precedente también ocupa un lugar importante dentro de las fuentes que soportan los argumentos de las y los administradores de justicia en los fallos analizados, al igual que la imposición de medidas de prevención en favor de las víctimas, que logra la aplicación de un mandato que por mucho tiempo permaneció en la retórica, así:

"En el caso que ocupa la atención del Despacho, si bien puede admitirse un estado de enervación en (el agresor), carácter que al parecer es cotidiano en su hogar, no podemos hablar de un comportamiento ajeno grave e injusto para edificar la ira. En este punto, no es dable pensar que ante la negativa de (la víctima) de tener relaciones sexuales con su pareja esta sea agredida de tal manera, de otra parte es necesario resaltar la libertad sexual que le asista a la pareja, para disponer de su cuerpo y de su voluntad, así mismo la reacción del imputado no fue repentina, toda vez que la negativa de su compañera a tener relaciones ocurrió la noche anterior a la de ocurrencia de los hechos. De otra parte, el comportamiento de la ofendida no fue injusto, por el contrario estuvo ajustado a derecho $y$ en este punto se comparte 10 expresado por el señor Fiscal, en el sentido de que la conducta asumida por el sindicado fue totalmente reprochable al agredir a su cónyuge, por causas injustificadas atentando no solo contra la integridad física, sino también con la libertad y dignidad humana de la ofendida. De la prueba referenciada, el Despacho llega a la conclusión de que no es procedente reconocer el disminuyente de la punibilidad de ira e intenso dolor, circunstancia que como se dejó anotado al inicio de este ítem no alcanza a desvirtuar la responsabilidad que le atañe en el delito de Lesiones Personales Dolosas." (Juz. Séptimo Penal Municipal Adjunto. 2006 - 0263. P. 13. 2009)

De otra decisión con perspectiva de género se extractó el siguiente texto:

"Debe subrayarse que la violencia familiar es un grave flagelo social que afecta a amplios 
segmentos de la población, especialmente a sectores más vulnerables, como en este evento las mujeres, razón por la cual en el ordenamiento interno, irradiado por diversos instrumentos internacionales, se ha venido desplegando medidas orientadas a prevenir todas las modalidades de violencia intrafamiliar y a proteger a las víctimas de las mismas, ejemplo de ello es la Ley 294 de 1996, modificada posteriormente por la Ley 575 de 2000, que en su artículo 60. señala que todas las medidas de protección en ella previstas se entienden sin perjuicio de las correspondientes acciones penales, cuando a ello hubiere lugar, y que cuando el hecho objeto de la queja constituyere delito o contravención, el funcionario de conocimiento, adoptará las medidas de protección consagradas en ella, y remitirá las diligencias adelantadas a las autoridades competentes".

"Pero la protección especial a la mujer frente a este injusto, se vio materializado en el Código Penal con la modificación introducida por la Ley 882 de 2004, al artículo 229 de la Ley 599 de 2000, al incluirla como víctima en la causal de agravación punitiva inicialmente prevista en beneficio de los menores, así ampliando la órbita de protección a los sectores más endebles de la sociedad, consagró que el delito acarrearía una sanción más severa si la víctima del maltrato fuere un menor, una mujer, un anciano, una persona que se encuentre en incapacidad o disminución física, sensorial y psicológica o quien se encuentre en estado de indefensión".

"Más recientemente, debe destacarse la promulgación de la Ley 1257 de 2008, por la cual se dictan normas de sensibilización, prevención y sanción de formas de violencia y discriminación contra las mujeres en claro acatamiento a las directrices internacionales que ya se venían implementando" .(Juz. Primero Penal Mpal. 2010 - 0120. P. 9. 2010)

Asimismo, la Sentencia 2012 - 00016, proferida el treinta (30) de mayo de 2012 por el Juzgado Segundo Penal del Circuito de Pasto que declaró la nulidad de la audiencia de formulación de imputación, frente al homicidio perpetrado por el señor L.M.L.M contra quien fuera su compañera permanente, conducta que en la mencionada diligencia sería calificada como agravada, pero se encontraría amparada por la figura de la ira e intenso dolor, circunstancias que le otorgó al acusado, el beneficio establecido en el artículo 351 del Código de Procedimiento Penal, equivalente a una rebaja del $50 \%$ de la pena a imponer.

Cabe anotar que los hechos que rodean el caso dan cuenta de una muerte causada por trauma craneoencefálico severo, ocasionado por un golpe contundente con un madero a la altura de la cabeza, circunstancia que a criterio del ente acusador obedeció a un estado de ira generado por la víctima en su agresor, dados los agravios verbales y físicos que permanentemente esta cometiera contra él, además de la existencia de una supuesta relación con otro hombre, calificación que sería ratificada y validada por la jueza de control de garantías.

Con estos antecedentes, el Juzgado Segundo Penal del Circuito advirtió:

"Es claro que la actitud y la conducta cometida por el sujeto activo, fue tendiente a demostrar la autoridad que pretendía ostentar, (...) donde fácilmente se observa que subyace el pensamiento patriarcal transferido por la cultura que desde la historia se ha manejado, dentro de la cual, existe gran inequidad de género que permitía a los hombres utilizar a las mujeres como si fuesen objetos, exigir sumisión y demostrar su poder incluso con agresiones; pero en la actualidad, con la existencia y aplicación de los derechos fundamentales y la protección especial que merece la mujer a raíz de la ratificación por parte de nuestro país de la "Convención de Belém Do Pará", mediante la ley 248 de 1995, que fue suscrita para proteger los derechos de la mujer y eliminar la violencia de género, la mujer esta investida de una protección especial tendiente a dar por terminada la discriminación que se ha ejercido en su contra desde la historia hasta nuestros días en la utilización del lenguaje, la cultura, la legalidad y judicialmente". (Sentencia 2012 - 00016, folio 47).

"Si las leyes sobre la igualdad y equidad de género, $(823 / 03,581 / 00)$, la Convención sobre la eliminación de todas las formas de discriminación contra la mujer, la Convención Interamericana para prevenir, sancionar y erradicar la violencia contra la mujer, "Convención de Belem Do Pará", (leyes 51/81, 19-02-82, 248/95), la Ley 1257 de diciembre 4 de 2008, se han adoptado por el Estado Colombiano, su aplicación debe hacerse efectiva comenzando por los estrados judiciales, de lo contrario resultaría inane el Pacto por los tres poderes del Estado a través de la Consejería Presidencial 
para la Equidad de la Mujer suscrito por las altas Cortes en el año 2003, de la búsqueda por consolidar y perfeccionar la aplicación de la transversalización de la perspectiva de género en la Administración de Justicia" .(Sentencia 2012 00016, folio 43)

"En este sentido la imputación jurídica realizada al señor L.M.L.M. (...) no ostenta la debida congruencia con los presupuestos fácticos, porque como se explicó, desde su narración fueron acomodados a la preconcepción atávica histórica y cultural que se ha hecho mención, por ende la circunstancia ya de ira o ya intenso dolor establecidas en el artículo 57 del Código Penal, en el presente caso no existieron". (Sentencia 2012 - 00016, folio 42)

Hallazgos como estos dan cuenta de un importante proceso de sensibilización hacia la materialización del verdadero concepto de equidad, realidad que motiva la continuidad y el impulso de procesos de investigación, de capacitación, sensibilización y acompañamiento a las víctimas que promuevan fuertes transformaciones, tal es el caso de la creación de la Clínica Jurídica con enfoque de Género de la Universidad de Nariño, propuesta que surge como resultado de los estudios en torno al tema y que se traduce en un valioso escenario para apoyar desde la Academia la defensa de los derechos de las mujeres, la construcción del concepto de nuevas masculinidades y la necesaria defensa de la diversidad.

\section{Sentencias Judiciales}

Juzgado Séptimo Penal Municipal Adjunto. 2006 0263. 2009.

Juzgado Primero Penal Municipal. 2010 - 0120. 2010.
Juzgado Segundo Penal del Circuito Sentencia 2012 - 00016.

\section{REFERENCIAS BIBLIOGRÁFICAS}

Ariza, G. (2012). De inapelable a intolerable. Violencia contra las mujeres en sus relaciones de pareja en Medellín. Bogotá: Universidad Nacional de Colombia.

Comisión Nacional de Género de la Rama Judicial (2011). Criterios de equidad para una administración de justicia con perspectiva de género.

Díaz, R. (2011). Presentación. En Criterios de equidad para una administración de justicia en perspectiva de género. Bogotá: Consejo Superior de la Judicatura.

Goyes, I., Montezuma, S. (2012) Informe regional. Derechos humanos de las mujeres y justicia de género en Nariño. En Memoria $1^{\circ}$ Encuentro nacional de investigadores en asuntos de género. Bogotá: Alta Consejería Presidencial para la equidad de la mujer.

Naciones Unidas. Convención para la eliminación de todas las formas de discriminación contra la mujer CEDAW. Consulta realizada el 5 de febrero de 2014 desde http://www.oas.org/dil/esp/Convencion_sobre_tod as_las_formas_de_Discriminacion_contra_la_Muje r.pdf

Organización de Estados Americanos. Convención para la eliminar, sancionar y erradicar la violencia contra la mujer. Consulta realizada el 15 de diciembre de 2013 desde http://www.oas.org/juridico/spanish/tratados/a-61. html 